\title{
Qualidade ambiental das nascentes do Rio Paraim, extremo sul do Piauí
}

Os pequenos fluxos de escoamento dão origem aos corpos hídricos que, por meio dos seus usos múltiplos, contribuem para a satisfação das necessidades vitais básicas dos animais, vegetais e ecossistemas. As áreas de nascentes desempenham importante função para a manutenção da qualidade ambiental da bacia. Para isso, é imprescindível que essas regiões possuam uma política eficaz de conservação. Desta forma, o objetivo do presente estudo foi determinar a qualidade ambiental das áreas de nascentes do rio Paraim, enfatizando os aspectos de qualidade físico-química e biológica das águas e caracterização das condiçc̃es ambientais locais por meio da avaliação macroscópica. Foram realizadas visitas em sete nascentes perenes do rio Paraim e, com a avaliação macroscópica foi possível identificar os impactos observados nas nascentes e áreas de preservação permanente, condições de acesso, proximidade com núcleos rurais e tipos de usos das nascentes. Foram avaliados os parâmetros físico-químicos e microbiológicos da água e confrontados com a Resolução no $357 / 2005$ do Conselho Nacional de Meio Ambiente (CONAMA) e Índice de Qualidade das Águas (IQA). A avaliação macroscópica das nascentes demostrou que 57,1\% das nascentes foram avaliadas em 'ótima' ou 'boa' situação e apenas uma única nascente foi qualificada como 'péssima'. A determinação do IQA das nascentes resultou em valores que variaram entre 59 e 86 no período seco; e entre 56 e 89 na pontuação do período chuvoso. Isso demonstra que todas as nascentes avaliadas apresentaram IQA satisfatórios ('bom' ou 'ótimo'). Com a avaliação da qualidade das águas foi possível observar a relação entre os parâmetros de qualidade, bem como a influência destes com as características macroscópicas das nascentes. Desta forma, as informações obtidas sinalizam que, apesar da boa qualidade das águas, a avaliação da situação ambiental das nascentes alerta para a necessidade de estratégias futuras, que visem o planejamento para o ordenamento territorial e gestão ambiental de microbacias hidrográficas.

Palavras-chave: Qualidade da água; Avaliação macroscópica; Qualidade ambiental; Recursos hídricos.

\section{Environmental quality of the Paraim River springs, far south of Piaui}

Small runoff flows give rise to water bodies that, through their multiple uses, contribute to meeting the basic vital needs of animals, plants and ecosystems. Spring areas play an important role in maintaining the environmental quality of the basin. For this, it is essential that these regions have an effective conservation policy. Thus, the objective of the present study was to determine the environmental quality of the Paraim River spring areas, emphasizing the aspects of physical-chemical and biological quality of the waters and characterization of local environmental conditions through macroscopic evaluation. Visits were carried out in seven perennial springs of the Paraim River and, with the macroscopic evaluation it was possible to identify the impacts observed in the springs and permanent preservation areas, access conditions, proximity to rural nuclei and types of uses of the springs. The physicochemical and microbiological parameters of water were evaluated and compared with Resolution No. 357/2005 of the National Environment Council (CONAMA) and Water Quality Index (IQA). The macroscopic evaluation of the springs showed that $57.1 \%$ of the springs were evaluated in 'excellent' or 'good' situation and only a single source was classified as 'terrible'. The determination of the IQA of the springs resulted in values ??that varied between 59 and 86 in the dry period; and between 56 and 89 in the rainy season score. This demonstrates that all the evaluated sources presented satisfactory IQA ('good' or 'great'). With the evaluation of the water quality it was possible to observe the relationship between the quality parameters, as well as their influence with the macroscopic characteristics of the springs. Thus, the information obtained indicates that, despite the good water quality, the assessment of the environmental situation of the springs warns of the need for future strategies, which aim at planning for territorial planning and environmental management of watersheds.

Keywords: Water quality; Macroscopic evaluation; Environmental Quality; Water resources.

Topic: Hidrogeografia

Reviewed anonymously in the process of blind peer
Received: $12 / 04 / 2019$

Approved: 27/05/2019
Israel Lobato Rocha (iD)

Instituto Federal do Piauí, Brasil

http://lattes.cnpq.br/6518724518793037

http://orcid.org/0000-0002-4496-9935

israel.lobato@ifpi.edu.br

Leandro Caixeta Salomão (iD)

Instituto Federal Goiano, Brasil

http://lattes.cnpq.br/0048021809961606

http://orcid.org/0000-0001-9436-1488

leandro.salomao@ifgoiano.edu.br

Bruna de Freitas Iwata (id

Instituto Federal do Piauí, Brasil

http://lattes.cnpq.br/3036032785449787

http://orcid.org/0000-0002-6465-9731

iwata@ifpi.edu.br

\author{
José Antonio Rodrigues de Souza (iD \\ Instituto Federal Goiano, Brasil \\ http://lattes.cnpq.br/1637300776838940 \\ http://orcid.org/0000-0003-3024-9424 \\ jose.antonio@ifgoiano.edu.br \\ Débora Astoni Moreira \\ Instituto Federal Goiano, Brasil \\ http://lattes.cnpq.br/0892554192927049 \\ http://orcid.org/0000-0002-8658-1269 \\ debora.astoni@ifgoiano.edu.br
}

\section{Referencing this:}

ROCHA, I. L.; SALOMÃO, L. C.; IWATA, B. F.; SOUZA, J. A. R.; MOREIRA D. A.. Qualidade ambiental das nascentes do Rio Paraim, extremo sul do Piauí. Revista Ibero Americana de Ciências Ambientais, v.10, n.3, p.385-399, 2019. DOI: http://doi.org/10.6008/CBPC2179$\underline{6858.2019 .003 .0032}$ 


\section{INTRODUÇÃO}

Em ambientes naturais, ocorrem diversas interações que são essenciais para a manutenção da vida e do equilíbrio ecológico. Pequenos fluxos de escoamento dão origem aos corpos hídricos que, por meio dos seus usos múltiplos, contribuem para a satisfação das necessidades vitais básicas dos animais e vegetais. As áreas de vegetação nativa devem estar com significativo grau de conservação para garantir a qualidade ambiental local (SILVA et al., 2017).

Os recursos hídricos são influenciados diretamente pela qualidade dos biomas e ecossistemas (WWDR, 2018). Assim, a deterioração das áreas florestadas, uso intensivo do solo e perda da biodiversidade, são impactos adversos que comprometem a integridade dos mananciais superficiais e subterrâneos. Mundialmente, a demanda hídrica é determinada conforme o crescimento populacional, a urbanização, políticas de segurança alimentar e energética (UNESCO, 2015). Isso possibilita, a intensificação das atividades exploratórias nas áreas adjacentes aos mananciais superficiais, resultando na mudança da paisagem e ocasionando impactos ambientais negativos que refletem em toda a área da bacia.

O Novo Código Florestal estabelece que as áreas de nascentes e olhos d'água, devem possuir a área de preservação permanente - APP, área protegida com função de preservar os corpos hídricos, paisagem e biodiversidade. A Lei Federal no 12.651 de 2012 determina que as APPs de nascentes devem possuir um raio de 50 metros (BRASIL, 2012).

A perda dos remanescentes florestais das áreas próximas aos mananciais potencializa a intensificação dos processos erosivos. O principal meio de transporte dos sedimentos erodidos é a água (MEDEIROS et al., 2009). Assim, a substituição da vegetação natural existente em toda a extensão das bacias, culmina na intensificação do processo de assoreamento dos corpos d'água.

Assim, as áreas de nascentes desempenham uma importante função para a manutenção da qualidade ambiental da bacia. Para isso, é imprescindível que essas regiões possuam uma política eficaz de conservação dos ecossistemas locais, manutenção da vegetação que envolve as áreas de afloramento das águas subterrâneas (olhos d'água), controle do uso do solo - evitando práticas que deteriorem os recursos ambientais - e recuperação de áreas degradadas. Desta forma, o objetivo do presente estudo foi determinar a qualidade ambiental das áreas de nascentes do rio Paraim, enfatizando os aspectos de qualidade físicoquímica e biológica das águas e caracterização das condições ambientais locais por meio da avaliação macroscópica.

\section{MATERIAIS E MÉTODOS}

\section{Área de estudo}

A bacia hidrográfica do rio Paraim possui uma área total aproximada de 8.634 quilômetros quadrados e o rio principal possui 204,42 quilômetros de comprimento (Mapa 1). Localiza-se na região hidrográfica do Parnaíba (MMA, 2006) e tem como principais afluentes os rios Corrente, Palmeiras, Riachão, Fundo e Curimatá (ANA, 2019). Nasce na base das escarpas da Chapada das Mangabeiras (NASCIMENTO et al., 2018) 
a uma altitude média de 595 metros. O clima da região em estudo, conforme o IBGE (2002), é tropical semiúmido com o período de cinco meses de estação seca. Apresenta as temperaturas mínimas médias de $20^{\circ} \mathrm{C}$ e máximas de $34^{\circ} \mathrm{C}$ e, precipitação pluviométrica acumulada anual de $980 \mathrm{~mm}$ (INMET, 2018).

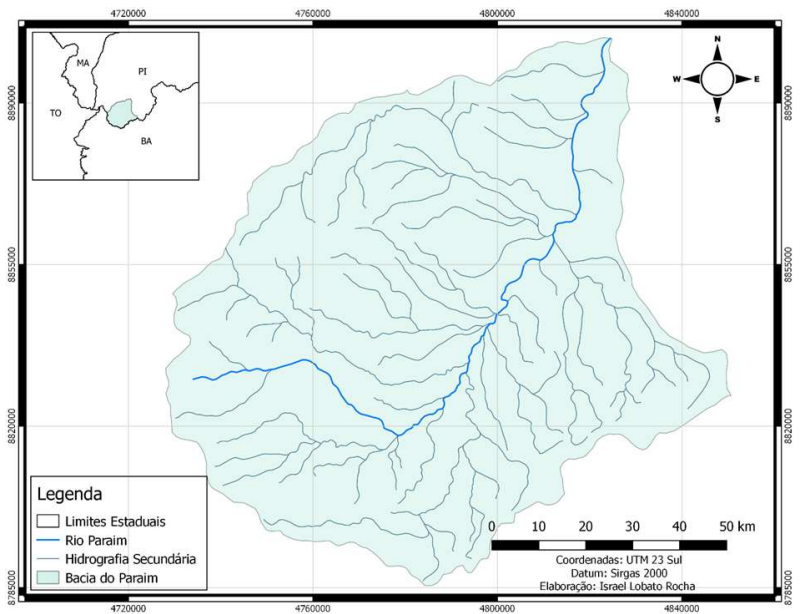

Mapa 1: Localização geográfica da bacia hidrográfica do rio Paraim. Fonte: ANA (2015).

O relevo da área de estudo é composto pelas Chapadas das Mangabeiras que apresentam perfis irregulares e sinuosos, formando escarpas bem definidas na parte superior, constituindo paredões com perfis verticalizados e destituídos em sua maioria de solos ou de cobertura vegetal (ICMBIO, 2018). O ponto mais alto da Chapada pode alcançar 880 metros de altitude (BRASIL, 2006).

\section{Procedimentos metodológicos}

\section{Identificação das nascentes}

Foram realizadas visitas in loco em sete nascentes perenes do rio Paraim (Tabela 1). A identificação dos pontos amostrais (nascentes) se deu por meio do conhecimento da população local, utilização de mapas, imagens de satélites e cartas cartográficas. A obtenção dos dados espaciais em campo (coordenadas) ocorreu com o uso de receptor GPS (Sistema de Posicionamento Global) e posteriormente foram elaborados mapas temáticos da área de estudo com o SIG (sistema de informações geográficas) Quantum GIS (QGIS) versão 2.0 Dufour. Para o desenvolvimento dos mesmos foram utilizadas as malhas municipais do IBGE, bem com arquivos de forma (shapefilles) dos corpos hídricos disponibilizados pela ANA e dados altimétricos da SRTM (Missão Topográfica por Radar do Ônibus Espacial) para a extração detalhada da drenagem da bacia em estudo.

Tabela 1: Distribuição dos pontos amostrais (nascentes) e respectivas coordenadas.

\begin{tabular}{|l|l|l|}
\hline Ponto & Nome da nascente & Coordenadas geográficas \\
\hline NASC 1 & Nascente da Tapera & $10^{\circ} 53^{\prime} 09^{\prime \prime} \mathrm{S} / 45^{\circ} 34^{\prime} 62^{\prime \prime} \mathrm{O}$ \\
\hline NASC 2 & Nascente da Prata & $10^{\circ} 53^{\prime} 01^{\prime \prime} \mathrm{S} / 45^{\circ} 35^{\prime} 82^{\prime \prime} \mathrm{O}$ \\
\hline NASC 3 & Nascente da Gia & $10^{\circ} 50^{\prime} 10^{\prime \prime} \mathrm{S} / 45^{\circ} 38^{\prime} 01^{\prime \prime} \mathrm{O}$ \\
\hline NASC 4 & Nascente Cabeceira & $10^{\circ} 49^{\prime} 95^{\prime \prime} \mathrm{S} / 45^{\circ} 38^{\prime} 03^{\prime \prime} \mathrm{O}$ \\
\hline NASC 5 & Nascente Grotas & $10^{\circ} 50^{\prime} 24^{\prime \prime} \mathrm{S} / 45^{\circ} 38^{\prime} 03^{\prime \prime} \mathrm{O}$ \\
\hline NASC 6 & Nascente Areais & $10^{\circ} 50^{\prime} 25^{\prime \prime} \mathrm{S} / 45^{\circ} 38^{\prime} 05^{\prime \prime} \mathrm{O}$ \\
\hline NASC 7 & Nascente das Pedras & $10^{\circ} 50^{\prime} 34^{\prime \prime} \mathrm{S} / 45^{\circ} 38^{\prime} 38^{\prime \prime} \mathrm{O}$ \\
\hline
\end{tabular}




\section{Avaliação macroscópica das nascentes}

Após o mapeamento dos pontos amostrais foi realizada a avaliação macroscópica das nascentes. Conforme metodologias adaptadas de Gomes et al. (2005), Felippe et al. (2012), Gomes (2015) e Leal et al. (2017), a avaliação macroscópica é um levantamento qualitativo que visa a identificação dos impactos ambientais em nascentes de cursos d'água. Durante a expedição às nascentes, foram observadas as seguintes variáveis qualitativas: impactos observados nas nascentes, impactos nas áreas de preservação permanente, condições de acesso, proximidade com núcleos rurais e/ou áreas urbanas, tipos de usos das nascentes, informações sobre a área de inserção, etc..

Para a avaliação macroscópica das nascentes, utilizou-se 14 parâmetros qualitativos, os quais foram classificados como ruim (1 ponto), médio (2 pontos) e bom (3 pontos), de acordo com a qualificação que cada um recebeu (Tabela 2). Desta forma, o resultado da avaliação varia de 14 pontos (em caso de todos os parâmetros serem considerados ruins) a 42 pontos (quando todos os parâmetros forem considerados bons).

Posteriormente, com a somatória dos pontos da avaliação, as nascentes foram classificadas conforme o grau de preservação em relação aos impactos ambientais observados nas áreas e enquadradas de acordo com a classe: A, B, C, D e E (GOMES et al., 2005; FELIPPE et al., 2012; GOMES, 2015; LEAL et al., 2017). Obtendo-se, desta forma, o Índice de Qualidade Macroscópica de Nascentes - IQMN (Tabela 3).

Tabela 2: Classificação das nascentes de acordo com a qualificação.

\begin{tabular}{|l|l|l|l|}
\hline \multirow{2}{*}{ Parâmetros } & Qualificação & Médio (2) & Bom (3) \\
\cline { 2 - 4 } & Ruim (1) & Clara & Transparente \\
\hline Cor da água & Escura & Cheiro fraco & Sem cheiro \\
\hline Odor da água & Cheiro forte & Poucos & Ausência \\
\hline Resíduos ao redor & Muitos & Poucos & Ausência \\
\hline Materiais flutuantes & Muitos & Poucas & Sem Espumas \\
\hline Espumas & Muitas & Poucos & Ausência \\
\hline Óleos & Muitos & Indícios & Sem Esgotos \\
\hline Esgoto na nascente & Visível & Alterada & Preservada \\
\hline Vegetação & Ausência & Apenas marcas & Não detectado \\
\hline Uso por animais & Presença & Apenas marcas & Não detectado \\
\hline Uso por humanos & Presença & Aceso razoável & Difícil acesso \\
\hline Acesso & Fácil acesso & Entre 50 e 100 m & Mais de 100 m \\
\hline Proximidade (urbanos) & Menos de 50 m & Moderada & Sem erosão \\
\hline Erosão nas margens & Acentuada & Propriedade privada \\
\hline Área de inserção & Informação Ausente & Unid. Conservação \\
\hline
\end{tabular}

Fontes: Adaptado de Gomes et al. (2005); Felippe et al. (2012); Gomes (2015) e Leal et al. (2017).

Tabela 3: Classificação das nascentes de acordo com o grau de preservação.

\begin{tabular}{|l|l|l|}
\hline Classe & Grau de preservação & Pontuação final \\
\hline A & Ótimo & $40-42$ \\
\hline B & Bom & $37-39$ \\
\hline C & Aceitável & $34-36$ \\
\hline D & Ruim & $31-33$ \\
\hline E & Péssimo & Abaixo de 30 \\
\hline
\end{tabular}

Fontes: Adaptado de Gomes et al. (2005); Felippe et al. (2012); Gomes (2015) e Leal et al. (2017).

\section{Avaliação da qualidade da água}

Para o levantamento da qualidade da água das principais nascentes, os pontos de amostragem foram as nascentes perenes do rio principal (rio Paraim). As coletas de amostras de água das nascentes ocorreram 
nos períodos seco (maio de 2018) e chuvoso (dezembro de 2018). A variabilidade sazonal foi observada de acordo com informações pluviométricas disponibilizadas pelo Instituto Nacional de Meteorologia (INMET), na estação automática localizada no Campus do Instituto Federal do Piauí, na cidade de Corrente (PI), código A374, com dados do ano de 2018 (INMET, 2018).

As amostras foram coletadas, acondicionadas e preservadas conforme o Guia Nacional de Coleta e Preservação de Amostras de Água (CETESB et al., 2011). Os parâmetros físico-químicos e microbiológicos constituintes do IQA (Índice de Qualidade das Águas) analisados foram: oxigênio dissolvido (OD), coliformes termotolerantes $(\mathrm{CT})$, potencial hidrogeniônico $(\mathrm{pH})$, temperatura, turbidez, fósforo, nitrogênio total, resíduo total e demanda bioquímica de oxigênio (DBO). As amostras foram encaminhadas para o laboratório de Água e Solos do Instituto Federal do Piauí - Campus Corrente e analisadas conforme método de referência Standard Methods (Tabela 4) da Associação Americana de Saúde Pública (APHA, 2012).

Tabela 4: Informações sobre as metodologias das análises laboratoriais, equipamentos adotados e unidades de medida das análises dos parâmetros físico-químicos e microbiológicos.

\begin{tabular}{|l|l|l|}
\hline Parâmetro & Método/Equipamento* & Unidade de medida \\
\hline Oxigênio dissolvido & Oxímetro (Lutron) - DO-5519 & $\mathrm{mg} / \mathrm{L}$ \\
\hline Temperatura & Termômetro digital - TE07 & ${ }^{\circ} \mathrm{C}$ \\
\hline C. termotolerantes & Meio cromogênio em DIP em papel - Colipaper & $\mathrm{NPM} / 100 \mathrm{~mL}$ \\
\hline $\mathrm{pH}$ & pHmetro (Lutron) - PH 221 & $\mathrm{UpH}$ \\
\hline $\mathrm{DBO}$ & Método volumétrico (Alfakit) & $\mathrm{mg} / \mathrm{L}$ \\
\hline Nitrogênio total & Fotocolorímetro (Alfakit) & $\mathrm{mg} / \mathrm{L}$ \\
\hline Fosforo total & Fotocolorímetro (Alfakit) & $\mathrm{mg} / \mathrm{L}$ \\
\hline Turbidez & Turbidimetro microprocessado (Alfakit) & $\mathrm{UNT}$ \\
\hline Resíduo total & Método gravimétrico & $\mathrm{mg} / \mathrm{L}$ \\
\hline
\end{tabular}

*Em conformidade com Standard Methods 21 ed. (2012) e ABNT NBR 12614 (1992).

\section{Índice de Qualidade das Águas - IQA}

O Índice de Qualidade das Águas - IQA foi formulado pela National Sanitation Foundation em 1970 nos Estados Unidos. Desde o ano 1975, o índice vem sendo utilizado pela Companhia Ambiental do Estado de São Paulo - CETESB (ANA, 2018). O IQA é composto por nove parâmetros e seus respectivos pesos. Esses pesos foram fixados de acordo com a conformação global da qualidade da água (ANA, 2017). Segundo a condição de cada um dos parâmetros, a metodologia estabeleceu curvas de variação da qualidade. Após a realização do cálculo, pode-se determinar o IQA das nascentes amostradas, conforme a variação de qualidade (Tabela 5).

Tabela 5: Classificação do IQA conforme o nível de qualidade.

\begin{tabular}{|l|l|l|}
\hline Classe & Categoria & Ponderação \\
\hline$A$ & Ótimo & $79<$ IQA $\leq 100$ \\
\hline B & Bom & $51<$ IQA $\leq 79$ \\
\hline C & Aceitável & $36<$ IQA $\leq 51$ \\
\hline$D$ & Ruim & $19<\mathrm{IQA} \leq 36$ \\
\hline E & Péssimo & IQA $\leq 19$ \\
\hline
\end{tabular}

Fonte: CETESB (2018). 


\section{RESULTADOS E DISCUSSÃO}

\section{Avaliação macroscópica das nascentes}

Na bacia do rio Paraim foram avaliadas, além das nascentes do brejo da Jia e da Prata, já identificadas pela Superintendência de Meio Ambiente de Corrente (CORRENTE, 2017), outras cinco nascentes foram catalogadas durante as visitas in loco. Totalizando sete nascentes perenes avaliadas, todas localizadas na zona rural do município de Corrente - PI (Mapa 2).

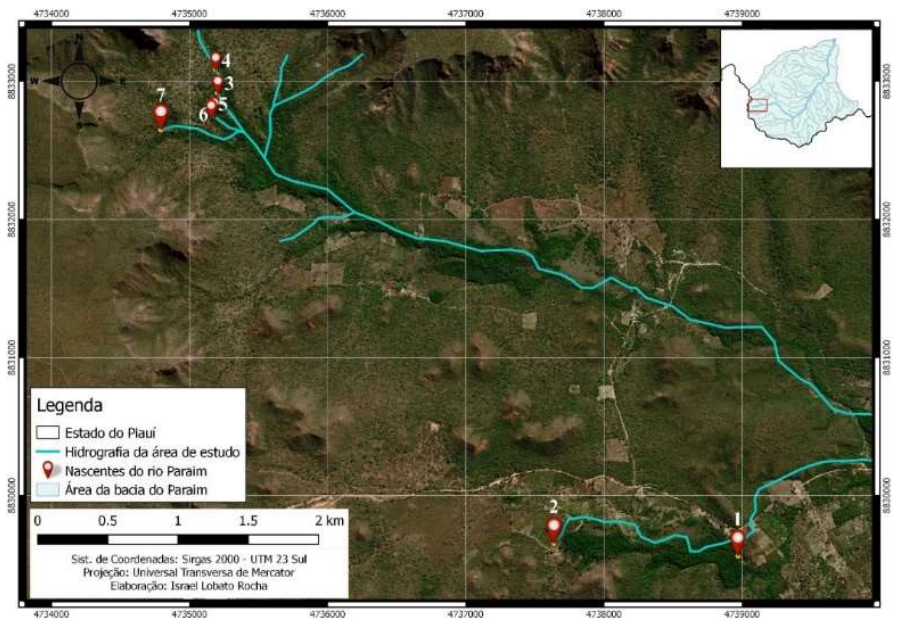

Mapa 2: Localização das nascentes. Fonte: ANA (2006).

A nascente do córrego Tapera (NASC. 1) está localizada em uma propriedade rural. O córrego Tapera é subafluente do rio Paraim e a vegetação é composta por mata de galeria com presença de Mauritia flexuosa (buriti). Em decorrência da proximidade de núcleos populacionais rurais e o acesso razoavelmente fácil, foram identificados indícios do uso pelos animais com a finalidade de dessedentação, bem como do homem, para a coleta do fruto do buriti nas margens. Por conta dessas utilizações, foram identificados processos erosivos nas margens e algumas espumas na água. Não foi registrada a presença de óleos e resíduos sólidos nas imediações da nascente e a água estava transparente (Figura 1).

Também localizada em uma propriedade particular, a nascente da Prata (NASC. 2) possui vegetação constituída por mata de galeria inundável com estado de conservação alterado e erosão moderada das margens. O cercamento nas proximidades dificulta o acesso de animais e contribui para a regeneração natural da vegetação. As águas da nascente possuem coloração transparente, sem odor, espumas, óleos e materiais flutuantes (Figura 1). Não foi identificada a presença de resíduo nas margens e nem compactação do solo. A nascente da Prata é a mais conhecida pela população e, consequentemente, a mais visitada. Isso ocorre devido à proximidade de núcleos populacionais rurais e estrada vicinal.

A nascente do brejo da Jia (NASC. 3) se localiza em uma área de veredas, solos hidromórficos, com a predominância da palmeira arbórea Mauritia flexuosa em meio a agrupamentos de vegetação arbustiva. Devido a distância de propriedades rurais (residências), não há indícios de presença de animais e uso humano na nascente. A água da nascente é transparente, sem odor, espumas, óleos e materiais flutuantes, além de não possuir indícios de resíduos sólidos nas margens (Figura 2-B). 


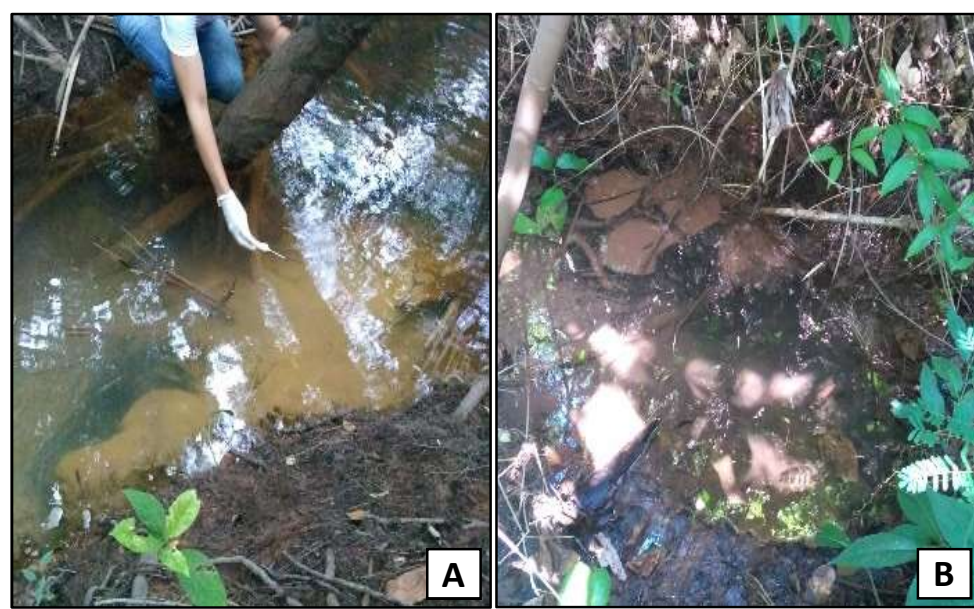

Figura 1: Nascente do córrego Tapera (A) e nascente da Prata (B).

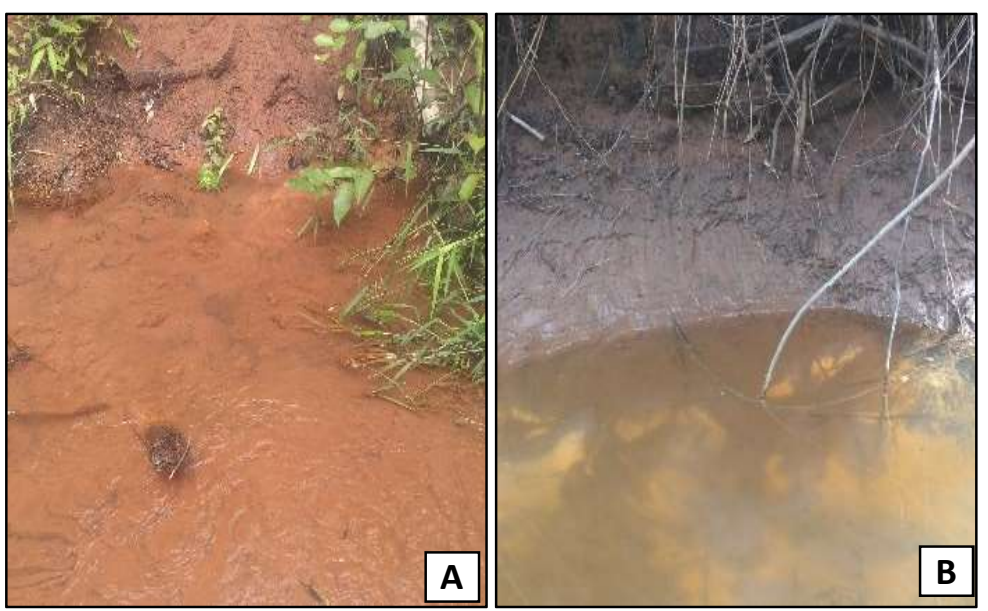

Figura 2: Nascente da Jia (A) e nascente Cabeceira (B).

À montante do brejo da Jia, encontra-se a nascente denominada 'Cabeceiras' (NASC. 4). Localizada a 370 metros do sopé da Chapada das Mangabeiras, Cabeceiras apresentou a menor pontuação dentre as nascentes avaliadas. Foram identificados vestígios de fogo nas áreas adjacentes, alteração na cor da água, odor, óleos, presença de materiais flutuantes e processos erosivos nas margens da nascente. A nascente está inserida nas proximidades de uma área que, recentemente, passou por desmatamento parcial da vegetação a fim de fazer o cercamento para criação de animais (pecuária).

Grotas e Areais são duas nascentes (NASC. 5 e 6) bastante próximas (Figura 3). Os seus escoamentos dão origem a um único curso d'água, que percorre cerca de 200 metros até desaguar no leito principal do rio Paraim. A fitofisionomia da nascente é mata de galeria com dossel fechado e cerrado típico nas suas adjacências. Apesar do registro de erosão e não haver informações sobre a área de inserção da nascente, os demais parâmetros obtiveram a pontuação máxima (3 pontos), ou seja, em conformidade com um ambiente preservado.

A Nascente das Pedras (NASC. 7), pouco conhecida inclusive pela população das localidades circunvizinhas, localiza-se na área com maior dificuldade de acesso (Figura 3C). A vegetação é caracterizada como mata de galeria, possuindo elevado grau de preservação, dossel fechado e nenhum vestígio de processos erosivos. As águas da nascente apresentaram transparência e ausência de cor, odor, óleos, materiais flutuantes, resíduos, espumas, além da ausência de indícios de uso da nascente por seres humanos 
e animais. Essas características fizeram com que a NASC. 7 obtivesse o melhor grau de preservação, dentre as nascentes avaliadas.
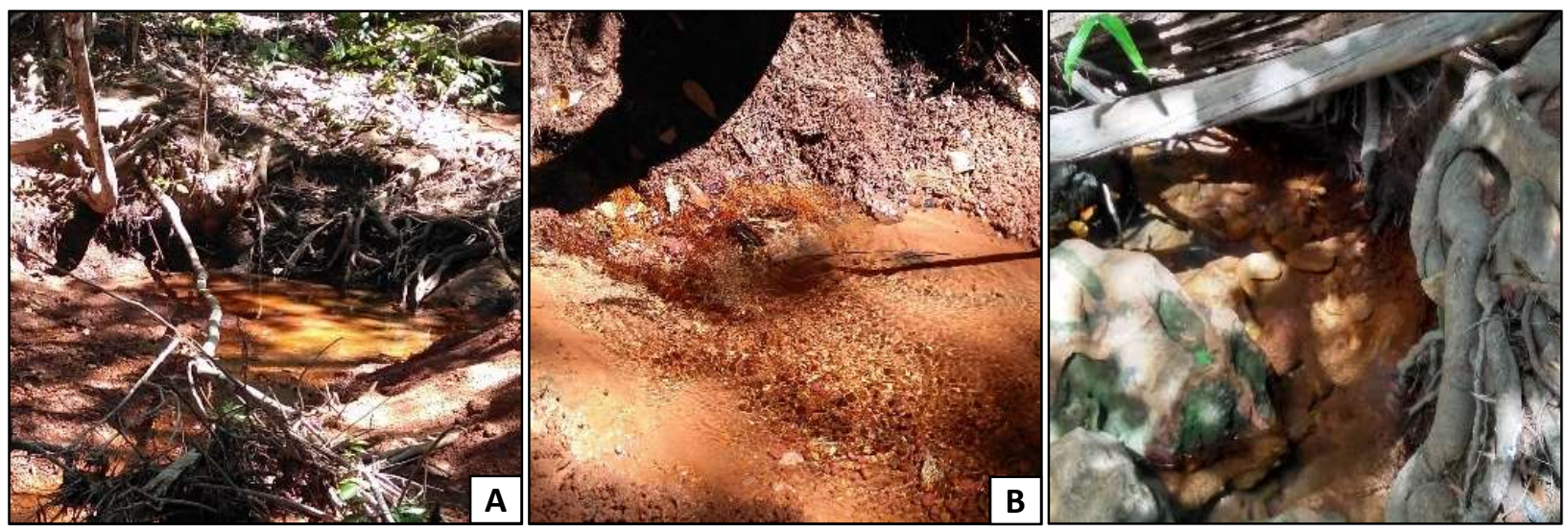

Figura 3: Nascente da Grotas (A), nascente Areais (B) e Nascente das Pedras (C).

Não houve o registro de resíduos sólidos e lançamento de esgoto em nenhuma das nascentes avaliadas, mesmo nas nascentes mais acessíveis. Esses resultados são indicativos de menor probabilidade de as nascentes estarem contaminadas (LEAL et al., 2016). Dentre as nascentes avaliadas, $42,9 \%$ apresentaram algum tipo espuma, sendo que o registro em três nascentes, está associado à presença de anfíbios nas áreas. Neves et al. (2013) registraram a presença de anfíbios nas nascentes do córrego mandacaru em Maringá/PR. Os anfíbios depositam seus em ninhos de espuma localizados na parte superficial dos corpos hídricos (VASCONCELOS et al., 2005).

A avaliação demostrou que a vegetação está preservada em $57,2 \%$ das nascentes, com vegetação nativa do bioma Cerrado e inserida, predominantemente, na fitofisionomia mata de galeria (RIBEIRO et al., 2008). Nenhuma das nascentes apresentou o solo completamente exposto e em três nascentes foram registrados algum tipo de alteração, principalmente por conta dos efeitos do fogo nas áreas.

Observou-se a presença de nascentes, predominantemente, em propriedades particulares (71,42\%). A vegetação apresentou algum tipo de alteração (supressão parcial) em 60 \% das nascentes localizadas em propriedades rurais. Os proprietários de imóveis rurais, da região em estudo, não registraram as nascentes do rio Paraim no sistema do Cadastro Ambiental Rural - CAR (Mapa 3).

Isso dificulta as ações de regularização ambiental no âmbito das propriedades, impossibilitando práticas efetivas de monitoramento, planejamento ambiental e combate ao desmatamento (BRASIL, 2012). Informações acerca do estágio de conservação das nascentes rurais auxiliam no planejamento de ações para reverter esse quadro de degradação e recorrente anormalidade (COUTINHO et al., 2018).

Dentre as nascentes avaliadas, nenhuma apresentou a pontuação máxima na avaliação macroscópica e uma única nascente foi qualificada como 'péssima'. Apenas uma nascente foi classificada com o grau de preservação 'ótimo' e três estavam em 'boa' situação. Sendo assim, 57,1\% das nascentes foram avaliadas em 'ótima' ou 'boa' situação (Tabela 6). 


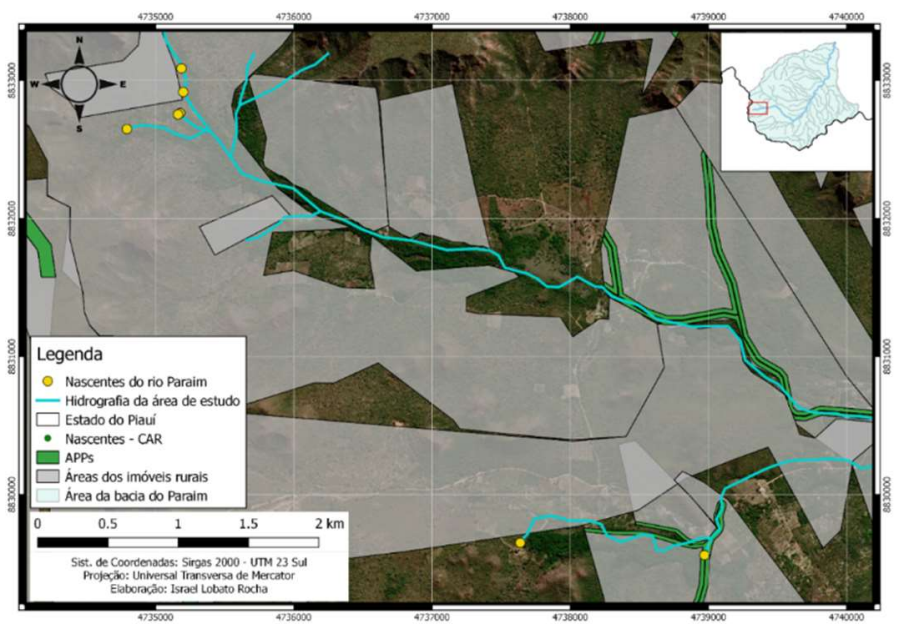

Mapa 3: Imóveis rurais na área de estudo registrados no sistema de Cadastro Ambiental Rural - CAR. Fonte: SICAR (2019).

Tabela 6: Avaliação macroscópica das nascentes avaliadas.

\begin{tabular}{|c|c|c|c|c|c|c|c|}
\hline \multirow[t]{2}{*}{ Parâmetro } & \multicolumn{7}{|c|}{ Nascentes avaliadas* } \\
\hline & Nasc 1 & Nasc 2 & Nasc 3 & Nasc 4 & Nasc 5 & Nasc 6 & Nasc 7 \\
\hline Cor da água & 3 & 3 & 3 & 2 & 3 & 3 & 3 \\
\hline Odor da água & 2 & 3 & 3 & 2 & 3 & 3 & 3 \\
\hline Resíduos ao redor & 3 & 3 & 3 & 3 & 3 & 3 & 3 \\
\hline Materiais flutuantes & 3 & 3 & 3 & 2 & 3 & 3 & 3 \\
\hline Espumas & 2 & 3 & 2 & 2 & 3 & 3 & 3 \\
\hline Óleos & 3 & 3 & 3 & 1 & 3 & 3 & 3 \\
\hline Esgoto na nascente & 3 & 3 & 3 & 3 & 3 & 3 & 3 \\
\hline Vegetação & 3 & 2 & 2 & 2 & 3 & 3 & 3 \\
\hline Uso por animais & 2 & 3 & 3 & 3 & 3 & 3 & 3 \\
\hline Uso por humanos & 2 & 3 & 3 & 2 & 3 & 3 & 3 \\
\hline Acesso & 2 & 2 & 2 & 3 & 3 & 3 & 3 \\
\hline Proximidade (rurais) & 3 & 2 & 3 & 3 & 3 & 3 & 3 \\
\hline Erosão nas margens & 2 & 2 & 1 & 1 & 2 & 2 & 2 \\
\hline Área de inserção & 2 & 2 & 2 & 2 & 1 & 1 & 2 \\
\hline Pontuação total & 35 & 37 & 36 & 29 & 39 & 39 & 41 \\
\hline Classe & $\mathrm{C}$ & $\mathrm{B}$ & $\mathrm{C}$ & $\mathrm{E}$ & $\mathrm{B}$ & $\mathrm{B}$ & $\mathrm{A}$ \\
\hline Grau & Aceitável & Boa & Aceitável & Péssima & Boa & Boa & Ótima \\
\hline
\end{tabular}

*NASC 1- Nascente da Tapera; NASC 2 - Nascente da Prata; NASC 3 - Nascente da Gia; NASC 4 - Nascente Cabeceira; NASC 5 - Nascente Grotas; NASC 6 - Nascente Areais; NASC 7 - Nascente das Pedras.

\section{Qualidade das águas das nascentes}

Os valores admissíveis dos parâmetros foram baseados na resolução do Conselho Nacional do Meio Ambiente - CONAMA no 357 de 2005, que dispõe sobre a classificação dos corpos de água conforme a classe de enquadramento. O rio Paraim - das nascentes até o seu exutório - não possui documento formal de aprovação do seu enquadramento, portanto é considerado de classe 2 (CONAMA, 2005).

A avaliação dos parâmetros físico-químicos e microbiológico da primeira campanha de coleta de água, realizada no período seco, demostrou que apenas as nascentes da Gia e Grotas não apresentaram nenhuma alteração nos parâmetros do IQA. O oxigênio dissolvido constitui-se como um dos principais parâmetros de qualidade da água, fornecendo subsídios necessários para a associação entre qualidade e a capacidade de autodepuração da água (AMORIM, 2017). Todas as nascentes avaliadas apresentaram valores de $O D$ em conformidade com a legislação vigente, variando entre $10,97 \mathrm{mg} / \mathrm{L}$ e $16,2 \mathrm{mg} / \mathrm{L}$, indicando uma ótica capacidade de aeração desses corpos de água.

As maiores concentrações de OD foram registradas nas nascentes Grotas, Pedras e Areais (média de 
15,4 mg/L). Isso pode ser explicado por conta do maior grau de entrelaçamento das copas das árvores, que influenciam na temperatura da água e, consequentemente, potencializa a solubilidade do oxigênio (CUNHA et al., 2010). Em nenhuma das nascentes avaliadas foi registrada a concentração de DBO acima do limite máximo estabelecido pela resolução CONAMA no 357 de 2005. Conforme a resolução o valor de DBO não poderá exceder $5 \mathrm{mg} / \mathrm{L}$ (CONAMA, 2005).

Observa-se, conforme as analises, uma relação entre DBO e coliformes termotolerantes: as nascentes Nasc 4 e Nasc 1 apresentaram os maiores valores de DBO (3,4 mg/L e 2,0 mg/L, respectivamente), apresentaram altas concentrações de coliformes termotolerantes. Agrizzi et al. (2018) constataram que, nas nascentes com bovinos no entorno, a presença elevada de coliformes se deu por conta das fezes desses animais e isso influenciou no aumento da DBO.

As nascentes com registros de presença de coliformes termotolerantes possuem influência direta com as atividades de pecuária realizadas na região. Apesar da ausência de registros de vestígios de animais nas nascentes (Nasc 1 e Nasc 4), a proximidade com locais de criação de animais possibilitou, através do escoamento superficial, a presença desse grupo de bactérias nas águas das nascentes da Tapera e Cabeceira. Estas estavam com os valores de 560 UFC/100 mL e 1520 UFC/100 mL (respectivamente), concentrações significativamente elevadas para esse tipo de classe de enquadramento (Classe 2) que estabelece ausência deste grupo de bactérias (CONAMA, 2005).

Os parâmetros nitrogênio total, turbidez e resíduo total apresentaram valores em conformidade com a resolução no 357/2005 do CONAMA. Já o fósforo total foi o parâmetro que mais apresentou concentrações acima do limite recomendado para corpos de água da classe 2. Quatro das sete nascentes apresentaram alterações nos níveis de fósforo total em suas águas. As maiores concentrações de fósforo total foram observadas nas nascentes da Gia, Cabeceira, Areais e Pedras, que apresentaram valores de 0,22 mg/L, 0,15 $\mathrm{mg} / \mathrm{L}, 0,17 \mathrm{mg} / \mathrm{L}$ e $0,24 \mathrm{mg} / \mathrm{L}$, respectivamente (Tabela 7). A proximidade dessas nascentes com a Chapada das Mangabeiras pode evidenciar que a aplicação de fertilizantes, nos empreendimentos agrícolas, na chapada esteja provocando o carreando de fósforo para as nascentes. Alves et al. (2017) relacionaram o aumento da concentração de fósforo no ribeirão das Abóboras em Rio Verde (GO) com a aplicação de fosfatados para produção agrícola e, consequente carreamento para o curso hídrico.

Sperling (2014A) apontou que o fósforo pode estar presente na água em decorrência da aplicação de fertilizantes nas adjacências. A presença de áreas agrícolas nas proximidades dos mananciais hídricos é o "escoamento de fertilizantes e agrotóxicos que potencializa a eutrofização dos ambientes aquáticos" (HAAS et al., 2018).

O potencial hidrogeniônico das amostras analisadas não variou significativamente entre as nascentes e apresentou valores próximos à neutralidade. Em todas as nascentes avaliadas o $\mathrm{pH}$ apresentou valores dentro do intervalo permitido. Esses resultados foram satisfatórios, visto que os corpos hídricos com pH entre 6 e 9 possibilita o desenvolvimento adequado da vida aquática (VIGIL, 2003, citado por ABREU et al., 2017). 
Tabela 7: Parâmetros físico-químicos e microbiológico da primeira campanha de coleta de água - Período Seco (maio/2018).

\begin{tabular}{|l|l|l|l|l|l|l|l|l|l|}
\hline \multirow{2}{*}{ Parâmetro } & \multirow{2}{*}{ Unid. ${ }^{*}$} & \multicolumn{2}{|l|}{ Nascentes avaliadas** } & VMP*** \\
\cline { 3 - 9 } & & Nasc 1 & Nasc 2 & Nasc 3 & Nasc 4 & Nasc 5 & Nasc 6 & Nasc 7 & \\
\hline OD & $\mathrm{mg} / \mathrm{L}$ & 13,9 & 14,02 & 10,97 & 12,33 & 16,2 & 14,8 & 15,2 & $\geq 5$ \\
\hline DBO & $\mathrm{mg} / \mathrm{L}$ & 2,0 & 1,3 & 1,1 & 3,4 & 1,2 & 0,9 & 0,8 & Até 5 \\
\hline Temperatura & ${ }^{\circ} \mathrm{C}$ & 26,35 & 26,9 & 25,1 & 27,2 & 27,2 & 26,8 & 27,1 & - \\
\hline Fósforo total & $\mathrm{mg} / \mathrm{L}$ & 0,1 & 0,22 & 0,01 & 0,15 & 0,04 & 0,17 & 0,24 & $\leq 0,1$ \\
\hline $\mathrm{pH}$ & & 6,3 & 6,6 & 6,1 & 6,7 & 7,1 & 6,4 & 6,5 & 6 a 9 \\
\hline Turbidez & $\mathrm{UNT}$ & 5,88 & 1,63 & 2,99 & 11,6 & 0,41 & 0,13 & 0,77 & Até 100 \\
\hline Nitrogênio Total & $\mathrm{mg} / \mathrm{L}$ & 0,32 & 0,56 & 1,23 & 0,26 & 1,3 & 1,4 & 0,98 & Até 2,18 \\
\hline Resíduo total & $\mathrm{mg} / \mathrm{L}$ & 13 & 14 & 53 & 118 & 17 & 14 & 15 & Até 500 \\
\hline C.T. $* * * *$ & UFC & 560 & 0 & 0 & 1520 & 0 & 0 & 0 & Ausente \\
\hline
\end{tabular}

*Unidade de medida; **NASC 1 - Nascente da Tapera; NASC 2 - Nascente da Prata; NASC 3 - Nascente da Gia; NASC 4

- Nascente Cabeceira; NASC 5 - Nascente Grotas; NASC 6 - Nascente Areais; NASC 7 - Nascente das Pedras. ***Valor Máximo Permitido para corpos hídricos de classe 2, CONAMA n. 357/2005; C.T.**** - Coliformes Termotolerantes.

A temperatura da água influência uma série de variáveis, dentre elas o pH (CETESB, 2017). Nas nascentes avaliadas, as que apresentaram menores valores de $\mathrm{pH}$ foram as que possuíam as menores temperaturas. Essa relação proporcional positiva também é respaldada nos estudos de Sperling (2014B) e Correio et al. (2016).

A temperatura, por sua vez, apresentou uma variação entre $25,1^{\circ} \mathrm{C}$ e $27,2^{\circ} \mathrm{C}$. Essa variação foi considerada em conformidade, visto que não extrapolou os limites de tolerância térmica dos ecossistemas estudados. A temperatura, fora desses limites, pode influenciar negativamente no crescimento e reprodução de organismos aquáticos (ANA, 2018).

$\mathrm{Na}$ segunda campanha de coleta (período chuvoso) observou-se a redução significativa da concentração de OD em todas as nascentes, sendo que em três delas, com proximidade com a Chapada das Mangabeiras, apresentaram valores abaixo do permitido pela Resolução CONAMA no 357/2005: nascente da Prata (3,7 mg/L), Grotas (3,2 mg/L) e Areais (3,4 mg/L). Isso pode ser explicado em decorrência dos maiores índices pluviométricos (no período chuvoso) possibilitarem o aumento do escoamento superficial (AMORIM et al., 2016), carreando matéria orgânica das áreas adjacentes e possibilitando a lixiviação de matéria orgânica difusa de origem florestal e antrópica (ABREU et al., 2017; CETESB, 2017).

A redução do OD implica no aumento da DBO (AMORIM et al., 2016; CETESB, 2017; ANA, 2018). A DBO indica o potencial de consumo de OD pela matéria orgânica presente na água (VON SPERLING, 2014). Assim, a alta concentração de DBO pode ser explicada em consequência do consumo de OD, principalmente pelos nutrientes (fósforo) e matéria orgânica florestal.

Outro destaque - para o período investigado - foi a presença de fosforo total acima do limite máximo permitido pela legislação em todas as nascentes (Tabela 8). O excesso de fósforo pode estar associado com o excesso de fertilizantes agrícolas (OLIVEIRA et al., 2013; MARMONTEL et al., 2015). O excesso de fósforo na água, em conjunto com nitrogênio, tem como consequência o processo de eutrofização dos cursos de água (CETESB, 2017). Esse processo consiste no aumento da matéria orgânica na água e pode reduzir a concentração de oxigênio dissolvido e ocasionar a mortandade de organismos aquáticos (MELO et al., 2019; NOGUEIRA et al., 2015). 
Tabela 8: Parâmetros físico-químicos e microbiológico da segunda campanha de coleta de água - Período Chuvoso (dezembro/2018).

\begin{tabular}{|l|l|l|l|l|l|l|l|l|l|}
\hline \multirow{2}{*}{ Parâmetro } & \multirow{2}{*}{ Unid. } & \multicolumn{6}{|l}{ Nascentes avaliadas** } & VMP*** \\
\cline { 3 - 10 } & & Nasc 1 & Nasc 2 & Nasc 3 & Nasc 4 & Nasc 5 & Nasc 6 & Nasc 7 & \\
\hline OD & $\mathrm{mg} / \mathrm{L}$ & 8,5 & 3,7 & 5,9 & 7,1 & 3,2 & 3,4 & 8,4 & $\geq 5$ \\
\hline DBO & $\mathrm{mg} / \mathrm{L}$ & 2,3 & 6,6 & 4,5 & 2,1 & 8,3 & 7,1 & 2,2 & Até 5 \\
\hline Temperatura & ${ }^{\circ} \mathrm{C}$ & 27,6 & 27,4 & 27,3 & 27,6 & 27,5 & 27,3 & 27,6 & - \\
\hline Fósforo total & $\mathrm{mg} / \mathrm{L}$ & 0,27 & 0,78 & 1,26 & 0,28 & 1,19 & 1,25 & 0,65 & $\leq 0,1$ \\
\hline $\mathrm{pH}$ & $\mathrm{UpH}$ & 6,9 & 7,4 & 7,6 & 7,3 & 7,4 & 7,1 & 7,1 & 6 a \\
\hline Turbidez & $\mathrm{UNT}$ & 5,21 & 3,19 & 0,68 & 4,64 & 1,11 & 0,19 & 0,22 & Até 100 \\
\hline $\begin{array}{l}\text { Nitrogênio } \\
\text { Total }\end{array}$ & $\mathrm{mg} / \mathrm{L}$ & 0,37 & 0,7 & 0,52 & 0,89 & 0,61 & 0,43 & 0,12 & Até 2,18 \\
\hline Resíduo total & $\mathrm{mg} / \mathrm{L}$ & 20 & 13 & 14 & 67 & 13 & 14 & 14 & Até 500 \\
\hline C.T. ${ }^{* * * *}$ & $\mathrm{UFC}$ & 1360 & 0 & 0 & 0 & 0 & 80 & 0 & Ausente \\
\hline
\end{tabular}

*Unidade de medida; **NASC 1 - Nascente da Tapera; NASC 2 - Nascente da Prata; NASC 3 - Nascente da Gia; NASC 4

- Nascente Cabeceira; NASC 5 - Nascente Grotas; NASC 6 - Nascente Areais; NASC 7 - Nascente das Pedras. ***Valor Máximo Permitido para corpos hídricos de classe 2, CONAMA n. 357/2005; C.T.**** - Coliformes Termotolerantes.

\section{Índice de qualidade das águas - IQA}

A determinação do IQA das nascentes resultou em valores que variaram entre 59 e 86 no período seco; e de 56 a 89 na pontuação do período chuvoso. Na primeira campanha de coletas de amostras nas nascentes, $71,4 \%$ das nascentes apresentaram o IQA 'ótimo' e as demais nascentes $(28,6 \%)$ foram avaliadas com o IQA 'bom'. No período seco, em decorrência da influência do OD, a proporção se inverteu: cinco $(71,4 \%)$ nascentes apresentaram IQA 'bom' e duas nascentes $(28,6 \%)$ com o IQA classificado como 'ótimo'.

Desta forma, todas as nascentes avaliadas apresentaram IQA satisfatórios ('bom' ou 'ótimo'). Entretanto o OD, por ser o parâmetro de maior peso no índice (CETESB, 2017), influenciou na redução da qualificação das nascentes no período chuvoso (Tabela 9). Isso se deve a alta precipitação no período (SPERLING, 2014a) que possibilita o aumento do escoamento superficial e lixiviação de agroquímicos (herbicidas e fertilizantes) para as nascentes, provocando o aumento na concentração de nutrientes (ROSENBOM et al., 2009; SILVA-JUNIOR et al., 2015; LEAL et al., 2017; VALENTE et al., 2018).

Apesar de ter apresentado alteração em todas as nascentes, durante o período chuvoso, o fósforo total não contribuiu significativamente para a redução da classificação do IQA, influenciou somente na redução do valor do índice, se comparado com nascentes que possuía baixa concentração no período seco (nascente da Gia).

Tabela 9: Síntese dos resultados do IQMN e IQA das nascentes do rio Paraim.

\begin{tabular}{|c|c|c|c|c|c|c|c|}
\hline Nascente & Nome & Valor do IQMN* & Grau IQMN & Valor do IQA ${ }^{1}$ & Classe IQA' & Valor do IQA & Classe IQA ${ }^{2}$ \\
\hline 1 & Tapera & 35 & Aceitável & 64 & $\overline{B o m}$ & 66 & Bom \\
\hline 2 & Prata & 37 & Bom & 81 & Ótimo & 72 & Bom \\
\hline 3 & Gia & 36 & Aceitável & 84 & Ótimo & 74 & Bom \\
\hline 4 & Cabeceira & 29 & Péssimo & 59 & Bom & 89 & Ótimo \\
\hline 5 & Grotas & 39 & Bom & 86 & ótimo & 66 & Bom \\
\hline 6 & Areais & 39 & Bom & 82 & Ótimo & 56 & Bom \\
\hline 7 & Pedras & 41 & Ótimo & 81 & Ótimo & 85 & Ótimo \\
\hline
\end{tabular}

*IQMN - Índice de qualidade macroscópica de nascentes; IQA - índice de qualidade das águas (período seco); IQA ${ }^{2}$ índice de qualidade das águas (período chuvoso). 


\section{CONCLUSÕES}

O Índice de qualidade macroscópica de nascentes (IQMN) evidenciou que os impactos ambientais negativos nas nascentes estão relacionados, principalmente, com os processos erosivos nas proximidades, falta de efetivação na proteção desses espaços e a facilidade de acesso às áreas possibilitando o uso, mesmo que ocasional, pelos animais e seres humanos. O índice de qualidade das águas (IQA) apresentou valores consideravelmente altos, demostrando a qualidade ambiental das nascentes. Apesar de alguns parâmetros estarem alterados, o IQA foi coerente com o enquadramento realizado e em conformidade com a Resolução no 357/2005 do CONAMA.

Com a avaliação da qualidade das águas foi possível observar a relação entre os parâmetros de qualidade, bem como a influência destes com as características macroscópicas das nascentes. Essa relação foi respaldada pela relação observada entre o aumento da concentração de nutriente (fósforo), redução do OD e consequente aumento da DBO. As desconformidades identificadas em alguns parâmetros evidenciam que os poluentes, de origem antrópica, podem ser conduzidos para as áreas de nascentes. Desta forma, as informações obtidas sinalizam que, apesar da boa qualidade das águas, a avaliação da situação ambiental das nascentes alerta para a necessidade de estratégias futuras, que visem o planejamento para o ordenamento territorial e gestão ambiental de microbacias hidrográficas.

\section{REFERÊNCIAS}

ABNT. Associação Brasileira e Normas Técnicas. NBR 12614: águas: determinação da demanda bioquímica de oxigênio (DBO): método de incubação $\left(20^{\circ} \mathrm{C}\right.$, cinco dias). Brasília: ABNT, 1992.

ANA. Agência Nacional de Águas. Conjuntura dos recursos hídricos no Brasil 2017: relatório pleno. Brasília: ANA, 2017.

ANA. Agência Nacional de Águas. Indicadores de qualidade: índice de qualidade das águas (IQA). Brasília: ANA, 2018.

ANA. Agência Nacional de Águas. Sistema Nacional de Informações Sobre Recursos Hídricos. Divisão Hidrográfica. Brasília: ANA, 2019.

AGRIZZI, D. V.; CECÍLIO, R. A.; ZANETTI, S. S.; GARCIA, G. O.; AMARAL, A. A.; FIRMINO, E. F. A.; MENDES, N. G. S.

Qualidade da água de nascentes do Assentamento Paraíso.

Eng. Sanit. Ambient., Rio de Janeiro, v.23, n.3, p.557-568, 2018. DOI: http://dx.doi.org/10.1590/s1413$\underline{41522018150701}$

ALVES, W. S.; SAANTOS, L. N. S.; MEDEIROS, V. S.; AQUINO, D. S.; MORAIS, W. A.; SALEH, B. B.; PEREIRA, V. C.; MOURA, D. M. B.. Avaliação da qualidade da água e estado trófico do ribeirão das Abóboras, em Rio Verde/GO, Brasil. Geociências, São Paulo, v.36, n.1, p.13-29, 2017.

APHA. American Public Health Association. Standard methods for the examination of water and wastewater. 22 Ed. Washington: APHA, 2012.

AMORIM, D. G.; CAVALCANTE, P. R. S.; SOARES, L. S.;
AMORIM, P. E. C.. Enquadramento e avaliação do índice de qualidade da água dos igarapés Rabo de Porco e Precuá, localizados na área da Refinaria Premium I, município de Bacabeira (MA). Eng. Sanit. Ambient., Rio de Janeiro, v.22, n.2, p.251-259, 2017. DOI: http://dx.doi.org/10.1590/s141341522016131212

ANDRADE JÚNIOR, A. S.; BASTOS, E. A.; SILVA, C. O.; GOMES, A. A. N.; FIGUEREDO JÚNIOR, L. G. M.. Atlas Climatológico do Estado do Piauí. Teresina: Embrapa Meio Norte, 2004.

BISOGNIN, R. P.; WEBER, F. H.; VIEIRA, L. F.; SILVA, B. R.; WOHLENBERG, P.; BOHRER, R. G.. Análise e divulgação da qualidade da água de nascentes, afluentes e ponto de captação do arroio Lajeado Erval Novo no município de Três Passos/RS. Revista Gestão \& Sustentabilidade Ambiental, v.6, n.2, p.44-55, 2017.

BRASIL. Ministério da Saúde. Portaria n.2.914: Dispõe sobre os procedimentos de controle e de vigilância da qualidade da água para consumo humano e seu padrão de potabilidade. Brasília: DOU, 2011.

BRASIL. Decreto n.7.830: Instituiu o Sistema de Cadastro Ambiental Rural, o Cadastro Ambiental Rural, estabelece normas de caráter geral aos Programas de Regularização Ambiental. Brasília: DOU, 2012.

BRASIL. Lei n.12.651: Dispõe sobre a proteção da vegetação nativa; altera as Leis nos 6.938, de 31 de agosto de 1981, 9.393, de 19 de dezembro de 1996, e 11.428, de 22 de dezembro de 2006; revoga as Leis nos 4.771, de 15 de setembro de 1965, e 7.754, de 14 de abril de 1989, e a Medida Provisória no 2.166-67, de 24 de agosto de 2001; e 
dá outras providências. Brasília: DOU, 2012.

BRASIL. Lei n.9.433: Institui a Política Nacional de Recursos Hídricos, cria o Sistema Nacional de Gerenciamento de Recursos Hídricos, regulamenta o inciso XIX do art. 21 da Constituição Federal, e altera o art. 1ㅇda Lei no 8.001, de 13 de março de 1990, que modificou a Lei no 7.990, de 28 de dezembro de 1989. Brasília: DOU, 1997.

CETESB. Companhia Ambiental do Estado de São Paulo. Guia nacional de coleta e preservação de amostras: água, sedimento, comunidades aquáticas e efluentes líquidos. São Paulo: CETESB, 2011

CETESB. Companhia Ambiental do Estado de São Paulo. Qualidade das águas interiores no estado de São Paulo 2017. São Paulo: CETESB, 2018

CONAMA. Ministério do Meio Ambiente. Resolução n.357: Dispõe sobre a classificação dos corpos de água e diretrizes ambientais para o seu enquadramento, bem como estabelece as condições e padrões de lançamento de efluentes, e dá outras providências. Brasília: CONAMA, 2005.

CORREIO, L. N. C.; CECCONELLO, S. T.; MORAES, P. B.; GUEDES, H. A. S.; CENTENO, A. N.; CECCONELLO, S. T. Análise temporal da qualidade da água de um arroio no sul do Rio Grande do Sul. Revista Thema, v. 14, n. 2, p. 109-119, 2016.

CORRENTE. Prefeitura Municipal de Corrente. Técnicos do Meio Ambiente avaliam preservação de nascentes. Brasília: CORRENTE, 2017.

COUTINHO, M. P.; GONÇALVES, D. A.; CARAM, R. O.; SOARES, P. V.. Áreas de inundação no trecho paulista da bacia do Rio Paraíba do Sul e nascentes do Cadastro Ambiental Rural. Urbe, Rev. Bras. Gest. Urbana, Curitiba, v.10, n.3, p.614-623, 2018. DOI:

http://dx.doi.org/10.1590/2175-3369.010.003.ao09

CUNHA, D. G. F.; CALIJURI, M. C.. Análise probabilística de ocorrência de incompatibilidade da qualidade da água com o enquadramento legal de sistemas aquáticos-estudo de caso do rio Pariquera-Açu (SP). Eng Sanit Ambient, v.15, n.4, p.337-346, 2010.

HAAS, A.; CONCEIÇÃO, S. R.; DESCOVI FILHO, L.; HENKES, J. A.. Delimitação e caracterização de APP através do uso de um sistema de informação geográfica (SIG): o caso das APP's nos cursos de água da sub-bacia do Lajeado Pardo, Noroeste do RS. Revista Gestão \& Sustentabilidade Ambiental, v.7, n.3, p.640-649, 2018

IBGE. Instituto Brasileiro de Geografia e Estatísticas. Mapa de clima do Brasil. Rio de Janeiro: IBGE, 2002.

ICMBIO. Instituto Chico Mendes de Conservação da Biodiversidade. Relatório Parametrizado: Unidade de Conservação: Parque Nacional das Nascentes do Rio Parnaiba. Brasília: ICMBio, 2018.

INMET. Instituto Nacional de Meteorologia. Normais Climatológicas do Brasil 1981-2010. Brasília: INMET, 2018.

FELIPPE, M. F.; MAGALHÃES JUNIOR, A. P.. Impactos ambientais macroscópicos e qualidade das águas em nascentes de parques municipais em Belo Horizonte/MG.
Geografias, v.8, n.2, p.8-23, 2012.

GOMES, P. M.; MELO, C.; VALE, V. S.. Avaliação dos impactos ambientais em nascentes na cidade de Uberlândia/MG: análise macroscópica. Sociedade \& Natureza, v.17, n.32, p.103-120, 2005

GOMES, E. R.. Diagnóstico e avaliação ambiental das nascentes da Serra dos Matões, município de Pedro II, Piauí. Tese (Doutorado em Geografia) - Universidade Estadual Paulista 'Júlio de Mesquita Filho', Rio Claro, 2015.

LEAL, M. S.; TONELLO, K. C.; DIAS, H. C. T.; MINGOTI, R.. Caracterização hidroambiental de nascentes. Revista Ambiente e Água, Taubaté, v.12, n.1, p.146-155, 2017.

MEDEIROS, P. H. A.; ARAÚJO, J. C.; ANDRELLO, A. C. Modelagem distribuída da produção de sedimentos em uma bacia hidrográfica e sua validação utilizando $137 \mathrm{Cs}$. In: SIMPÓSIO BRASILEIRO DE RECURSOS HÍDRICOS, 18. Anais. Campo Grande, 2009

MELO, M. T.; QUEIROZ, T. M.; VINAGA, L. FERREIRA, J. R. S.; MARCHETTO, M..Variabilidade das classes de água e índice de estado trófico do riacho Queima Pé. Revista Engenharia na Agricultura-REVENG, v.27, n.1, p.68-79, 2019.

NEVES, P. D. M.; SOUZA, M. L.. Caracterização geoambiental da área de preservação permanente das nascentes do curso superior da bacia do Córrego Mandacaru do município de Maringá/PR: aspectos legais. Geo UERJ, v.1, n.24, p.386-406, 2013.

MMA. Ministério do Meio Ambiente. Caderno da Região Hidrográfica do Parnaíba. Brasília: MMA, 2006.

NOGUEIRA, P. F.; CABRAL, J. B. P.; OLIVEIRA, S. F.; ROCHA, I. R.. Eutrofização no reservatório da UHE foz do Rio Claro (GO). Revista do Departamento de Geografia, v.30, p.19-33, 2015. DOI: https://doi.org/10.11606/rdg.v30i0.90090

UNESCO. Organização das Nações Unidas para a Educação, a Ciência e a Cultura. Água para um mundo sustentável: Relatório Mundial das Nações Unidas sobre Desenvolvimento dos Recursos Hídricos: Sumário Executivo. Roma: UNESCO, 2015.

RIBEIRO, J. F.; WALTER, B. M. T.. Fitofisionomias do bioma Cerrado. In: SANO, S. M.; ALMEIDA, S. P.; RIBEIRO, J. F.. Cerrado: ecologia e flora. Brasília: Embrapa Informação Tecnológica, 2008

ROSENBOM, A. E.; KLAER, J.; HENRIKSEN, T. ULLUM, M.; OLSEN, P.. Ability of the macro model to predict long-term leaching of metribuzin and diketometribuzin. Environmental Science \& Technology, v.43, n.9, p.3221-3226, 2009. DOI: http://dx.doi.org/10.1021/es802752x

SILVA, G. B. S.; BERGIER, I.; PRADO, R. B.; FERRAZ, R. P. D.. Diagnóstico dos serviços ambientais florestais nos biomas brasileiros de 2001 a 2011. Corumbá: Embrapa Pantanal, 2017.

SILVA JÚNIOR, A. C.; QUEIROZ, J. R. G.; MARTINS, D. Quantidade de chuva e lixiviação do herbicida metribuzin através de planta bioindicadora. Revista Brasileira de Engenharia Agrícola e Ambiental, v.19, n.6, p.592-597, 
2015.

SPERLING, M. V.. Estudos e modelagem da qualidade da água de rios. 2 ed. Belo Horizonte: UFMG, 2014A.

SPERLING, M. V.. Introdução à Qualidade das Águas e ao Tratamento de esgotos. 4 ed. Belo Horizonte: UFMG, 2014B.

VALENTE, J. P. S.; PADILHA, P. M.; SILVA, A. M. M.. Contribuição da cidade de Botucatu-SP com nutrientes (fósforo e nitrogênio) na eutrofização da represa de Barra
Bonita. Eclética Química Journal, v.22, n.1, 2018.

VASCONCELOS, T. S.; FERES, D. C. R.. Diversidade, distribuição espacial e temporal de anfíbios anuros (Amphibia, Anura) na região noroeste do estado de São Paulo, Brasil. Biota Neotropica, v.5, n.2, p.137-150, 2005.

WWDR. World Water Development Report. Nature-based solutions for water: executive summary. Colombella: UNESCO, 2018

A CBPC - Companhia Brasileira de Produção Científica (CNPJ: 11.221.422/0001-03) detém os direitos materiais desta publicação. Os direitos referem-se à publicação do trabalho em qualquer parte do mundo, incluindo os direitos às renovações, expansões e disseminações da contribuição, bem como outros direitos subsidiários. Todos os trabalhos publicados eletronicamente poderão posteriormente ser publicados em coletâneas impressas sob coordenação da Sustenere Publishing, da Companhia Brasileira de Produção Científica e seus parceiros autorizados. Os (as) autores (as) preservam os direitos autorais, mas não têm permissão para a publicação da contribuição em outro meio, impresso ou digital, em português ou em tradução. 